University for Business and Technology in Kosovo

UBT Knowledge Center

UBT International Conference

2015 UBT International Conference

Nov 7th, 9:00 AM - 5:00 PM

\title{
Impact of shunt compensation in improving voltage level of overhead transmission lines
}

\author{
Marjola Puka \\ Polytechnic University of Tirana, marjolapuka@gmail.com \\ Nako Hobdari \\ Polytechnic University of Tirana, nakohobdari@yahoo.com \\ Leonard Gjini \\ Polytechnic University of Tirana, nardi_gjini@yahoo.com \\ Marjela Qemali \\ Polytechnic University of Tirana, m_qemali@yahoo.com
}

Follow this and additional works at: https://knowledgecenter.ubt-uni.net/conference

Part of the Engineering Commons

\section{Recommended Citation \\ Puka, Marjola; Hobdari, Nako; Gjini, Leonard; and Qemali, Marjela, "Impact of shunt compensation in improving voltage level of overhead transmission lines" (2015). UBT International Conference. 48. https://knowledgecenter.ubt-uni.net/conference/2015/all-events/48}

This Event is brought to you for free and open access by the Publication and Journals at UBT Knowledge Center. It has been accepted for inclusion in UBT International Conference by an authorized administrator of UBT Knowledge Center. For more information, please contact knowledge.center@ubt-uni.net. 


\title{
Impact of shunt compensation in improving voltage level of overhead transmission lines
}

\author{
Marjola Puka ${ }^{1}$, Nako Hobdari ${ }^{2}$, Leonard Gjini ${ }^{3}$, Marjela Qemali ${ }^{4}$ \\ Electrical Engineering Faculty, Polytechnic University of Tirana, Tirana, Albania \\ marjolapuka@gmail.com ${ }^{1}$,nakohobdari@yahoo.com², nardi_gjini@yahoo.com ${ }^{3}$, \\ m_qemali@yahoo.com ${ }^{4}$
}

\begin{abstract}
Shunt compensation is widely used in alternative current transmission and distribution networks to produce reactive power support. Located in critical points such as vicinity of load centers, the use of Shunt compensation has beneficial effect on power system performance. The focus of this paper is a case-study in Albanian Power System: the implementation of Shunt Compensation in transmission network. For the most critical part of the network, there are performed simulations in two situations: without reactive compensation and with shunt compensations. The simulations data results to be in compliance with measurements data of the voltage for overhead transmission lines at levels $110 \mathrm{kV}$ and $220 \mathrm{kV}$. By this way, the paper presents the impact of shunt compensation in improving voltage level of transmission network.।
\end{abstract}

Keywords: reactive power; shunt compensation; transmission line; voltage

\section{Introduction}

Except in a very few special situations, electrical energy is generated, transmitted, distributed and utilized as alternating current (AC). However alternating current has several distinct disadvantages. One of these is the necessity of reactive power that needs to be supplied along with active power. Reactive power can be leading or lagging. While it is the active power that contributes to the energy consumed, or transmitted, reactive power does not contribute to the energy. Reactive power is an inherent part of the "total power". Reactive power is either generated or consumed in almost every component of the system, generation, transmission and distributions and eventually by the loads. The impedance of a branch of a circuit in an AC system consists of two components: resistance and reactance.

Reactance can be either inductive or capacitive, which contribute to reactive power in the circuit. Most of the loads are inductive, and must be supplied with lagging reactive power. It is economical to supply the reactive power closer to the load in the distribution system.

Reactive power compensation in power systems can be either shunt or series. The focus of this paper is shunt compensation at substation level, whose priority is:

- Voltage regulation

The main reason that shunt capacitors are installed at substations is to control the voltage within required levels, especially for maximum loads, which vary depending on the hours in a day; it varies from weekday to weekend or it occurs between the months in a year time.

As the load varies, voltage at the substation bus and at the load bus varies. Since the load power factor is always lagging, a shunt connected capacitor bank at the substation can raise voltage when the load is high. The shunt capacitor banks can be permanently connected to the bus (fixed capacitor bank) or can be switched as needed. Switching can be based on time, if load variation is predictable, or can be based on voltage, power factor, or line current.

- Reducing power losses

Compensating the load lagging power factor with the bus connected shunt capacitor bank improves the power factor and reduces current flow through the transmission lines, transformers, generators, etc. This will reduce power losses $\left(I^{2} \mathrm{R}\right.$ losses $)$ in this equipment.

- Increasing utilization of equipment 
Shunt compensation with capacitor banks reduces kVA loading of lines, transformers, and generators, which means with compensation they can be used for delivering more power without overloading the equipment

\section{Reactive Power Compensation and AC Transmission}

The analy sis begins with basic principal of power compensation in transmission system [1] as shown in the simplified model shown in fig.1. Two power grids are connected by a transmission line which is assumed lossless and represented by a reactance $\boldsymbol{X}_{\boldsymbol{L}}$.

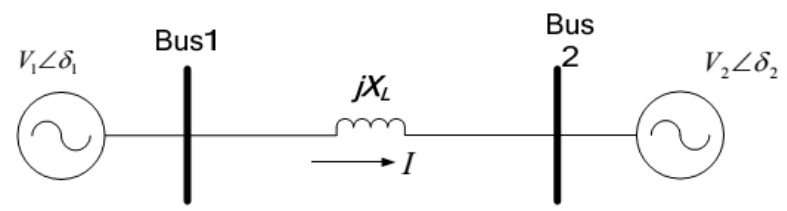

Fig.1.The simplified model of power transmission system

The angle between two connected buses is:

$\delta=\delta_{1}-\delta_{2}$

The fig. 2 represents the corresponding phasor diagram. The magnitude of the current in the transmission line is given by the expression:

$I=\frac{V_{L}}{X_{L}}=\frac{\left|V_{1} \angle \delta_{1}-V_{2} \angle \delta_{2}\right|}{X_{L}}$

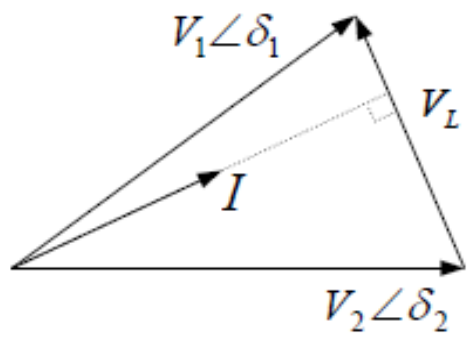

Fig.2. Phasor diagram of power transmission system

The active and the reactive components of current flow at bus 1 are given by:

$$
I_{d 1}=\frac{V_{2} \sin \delta}{X_{L}}, \quad I_{q 1}=\frac{V_{1}-V_{2} \cos \delta}{X_{L}}
$$

The active and the reactive power at bus 1 , are given by:

$$
P_{1}=\frac{V_{1} V_{2} \sin \delta}{X_{L}}, \quad \mathrm{Q}_{1}=\frac{V_{1}\left(V_{1}-V_{2} \cos \delta\right)}{X_{L}}
$$

Similarly, for the currents flow at bus 2, we can write the expressions:

$$
I_{d 2}=\frac{V_{1} \sin \delta}{X_{L}}, \quad I_{q 2}=\frac{V_{2}-V_{1} \cos \delta}{X_{L}}
$$

and for the power at bus 2 results the expressions:

$$
P_{2}=\frac{V_{1} V_{2} \sin \delta}{X_{L}}, \quad \mathrm{Q}_{2}=\frac{V_{2}\left(V_{2}-V_{1} \cos \delta\right)}{X_{L}}
$$


The above equations indicate that the active and reactive power can be regulated by controlling the voltage, phase angles and line impedance of power transmission system.

Generally the compensation of transmission systems can be divided in two main groups: shunt and series compensation. The first one is our focus, so we go on the analy sis of shunt compensation.

\subsection{Shunt Compensation}

Shunt compensation has been widely used in transmission system to regulate the voltage magnitude, to improve the voltage quality and to enhance the system stability Shunt-connected capacitors are used to maintain the voltage levels by compensating the reactive power to transmission lines. A simplified model of transmission system with shunt compensation is shown in fig.3, where a controlled capacitor $\boldsymbol{C}$ is shunt-connected at the midpoint of transmission line. The voltage magnitude at the connection point is maintained as $\boldsymbol{V}$.

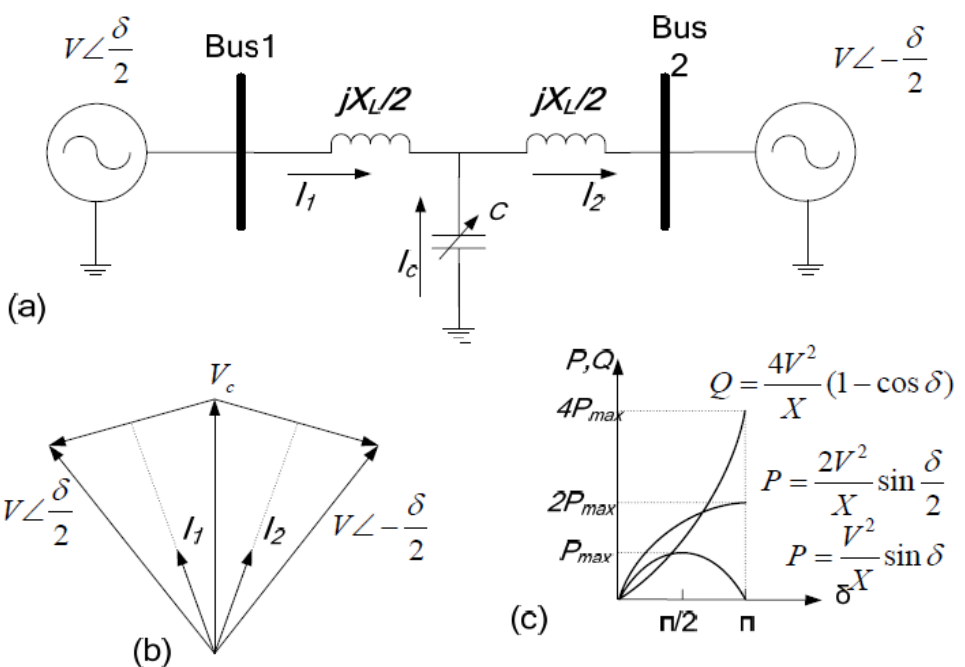

Fig.3. Transmission system with shunt compensation: (a) simplified model, (b) phasor diagram, (c) power-angle curve

The active power at bus 1 and bus 2 are equal:

$$
P_{1}=P_{2}=2 \frac{V^{2}}{X_{L}} \sin \frac{\delta}{2}
$$

The injected reactive power by the cap acitor to regulate the voltage at the midpoint of the transmission line is calculated as:

$$
Q_{C}=4 \frac{V^{2}}{X_{L}}\left(1-\cos \frac{\delta}{2}\right)
$$

From the power angle curve shown at fig.3.c, the transmission power can significantly increases at the peak point shifts from $\delta=90^{\circ}$ to $\delta=180^{\circ}$. The operation margins of the system stability are increased by the shunt compensation. The voltage support as function of midpoint compensation can easily be extended to the voltage support at the end of the radial transmission. The reactive power compensation at the end of the radial line is especially effective in enhancing voltage stability.

\subsection{Flexible AC Transmission System-FACTS}

FACTS (Flexible AC Transmission System) as the idea of power electronics applications in power compensation, began at 1970 [2]. Defined in IEEE terms, there are two important parts: 
- $\quad$ FACTS as alternative current transmission systems incorporating power electronicbased and other static controllers to enhance the controllability and increase power transfer capability.

- $\quad$ FACTS Controller as a power electronic-based system and other static equipment that provide control of one or more AC transmission parameters.

As a new technology of power transmission sy stem, FACTS and FACTS controllers not only provide the same benefits as traditional compensators with mechanically-controlled switches in steady states, but also improve the dy namic and transient performance of the power sy stem. The power electronicsbased switches in the functional blocks of FACTS can usually be operated repeatedly and the switching time is a portion of a periodical cycle, which is much shorter than the conventional mechanical switches. The advance of semiconductors increases the switching frequency and voltageampere ratings of the solid switches and facilitates the applications.

Shunt-connected FACTS controllers can be impedance ty pe, based on thy ristors without gate-turn off capability, which are called Static VAR Compensator (SVC) for shunt-connected application. Another type of FACTS controllers is converter-based which is usually in the form of a Static Synchronous Compensator (STATCOM).

\subsection{Static Var Compensator (SVC)}

Static Var Compensator (SVC) is a shunt-connected static Var generator or absorber, whose output is adjusted to exchange capacitive or inductive current, so as to maintain or control specific parameters of the electrical power system (typically bus voltage). SVC is based on thy ristors without gate-turn off capability [2], [3], [4]. The operating principal and characteristics of thyristors realize SVC variable reactive impedance. SVC includes two main components and their combination: (1) Thy ristor-controlled and Thy ristor-switched Reactor; and (2) Thy ristor-switched Cap acitor. The fig.4 shows the diagram of SVC. TCR and TSR are both composed of a shunt-connected reactor controlled by two parallel, reserved-connected thy ristors. TSC shares similar composition and same operational mode as TSR, but the reactor is replaced by a capacitor. With different combinations of TCR/TSR, TSC and fixed capacitors, a SVC can meet various requirements to absorb/supply reactive power from/to the transmission line. This is clear from the volt-ampere characteristic of SVC which is presented at fig.5.

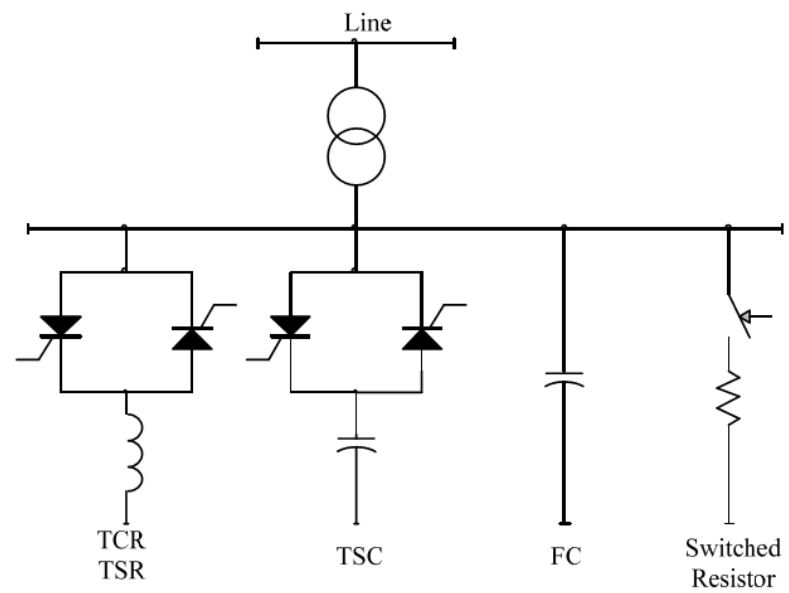

Fig.4. Static Var Compensators (SVC): TCR/TSR, TSC, FC and Mechanically Switched Resistor 


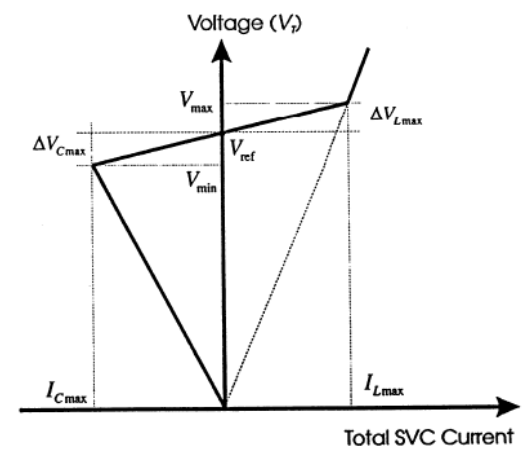

Fig.5. V-I Characteristic of SVC

\subsection{Converter- Based Compensator}

Static Synchronuos Compensator (STATCOM) is one of the key Converter-based Compensators, which are based on voltage source inverter (VSI) or current source inverter (CSI), as shown in fig.6. Unlike SVC, STATCOM controls the output current independently of the AC system voltage, while the DC side voltage is automatically maintained to serve as a voltage source.

Compared with SVC, the topology of a STATCOM is more complicated. The switching device of a VSI is usually a gate turn-off device paralleled by a reverse diode; this functions endows the VSI advanced controllability. Various combinations of the switching devices and appropriate topology make it possible for a STATCOM to vary the AC output voltage in both magnitude and phase. Also, the combination with a storage device or power source (as shown in fig.6.b) endows the STATCOM the ability to control the real power output.

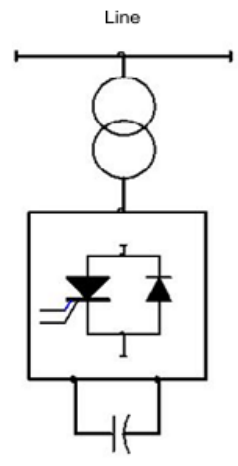

(a)

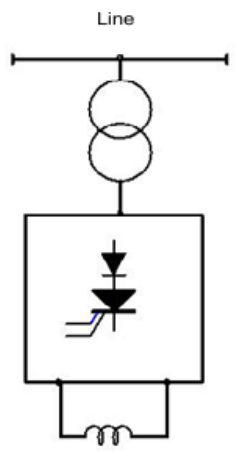

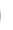

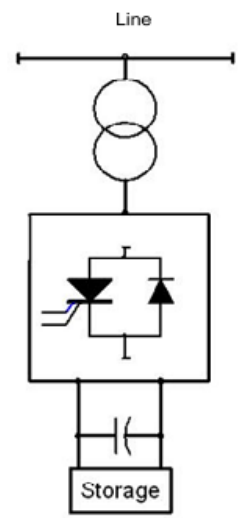

(b)

Fig.6. STATCOM topologies: a) based on VSI and CSI, b) STATCOM with Storage

STATCOM has much better dynamic performance than conventional reactive power compensators like SVC. The gate turn-off ability shortens the dynamic response time from several utility period cycles to a portion of a period cycle. So, STATCOM is much faster in improving the transient response than a SVC. This advantage brings higher reliability and larger operating range. It seems clear in the VA characteristic of STATCOM as shown in fig.7, compared with the SVC characteristic of fig. 5 . 


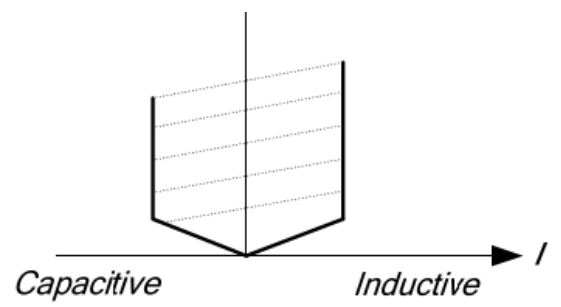

Fig 7. V-I characteristic of STATCOM

\section{The Reactive Compensation in Transmission System: Case-Study in Albanian Power System}

The Transmission System in Albania is composed of the 400, 220 and $110 \mathrm{kV}$ level networks. The $220 \mathrm{kV}$ network is completely meshed and connects the main plants in the North of Albania with the load centers in the areas of Tirana, Elbasan and Fieri. The $110 \mathrm{kV}$ network is used for the supply of the Distribution System. The Albanian power system is composed in such way that the main power plants which produce $90 \%$ of electricity are centralized in the north of Albania; meantime the main loads are in the centre (Tirana - Elbasan areas) and in the south (Fieri area). As the generation is located mainly in the north of the country, voltage profile trends to be slightly low in the southern part of the network [5], [6]. In this situation, the compensation of reative power at southern nodes of transmission network is the best economical short-term solution, compared with long-term investments of new transmission lines [4], [5]. There are predicted three main south nodes which have the most influence in reactive power consumption: Fier, Lushnja and Ballsh. In the scheme of fig. 8 is shown the scheme of Albanian power system from the generation nodes till the end transmission nodes: with highlighted part (see red arrow) is shown the nodes where is installed shunt compensation . The simulations are realized in two situations a) without reactive compensation and b) with shunt compensation performed of SVC device.

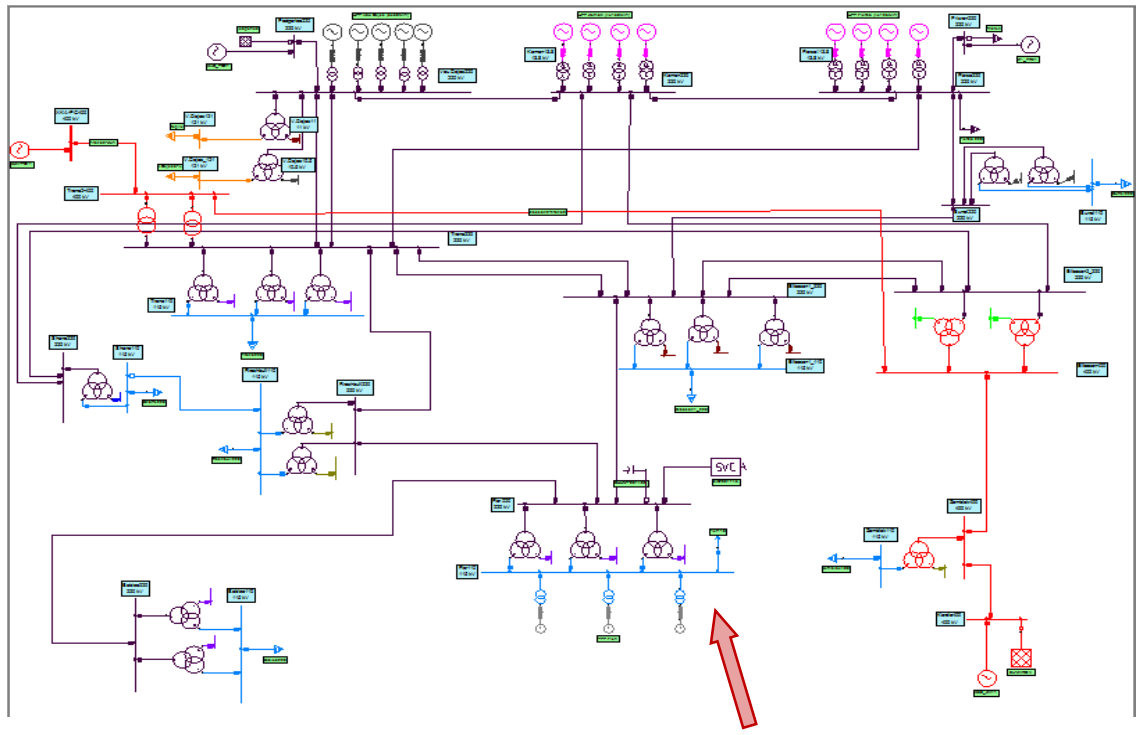

Fig.8. Scheme of the Albanian power system in NEPLAN software: red pointer shows the three nodes where are installed shunt compensation with fixed capacitor banks 
The fig. 9,10 represent the results of simulation for the $110 \mathrm{kV}$ and $220 \mathrm{kV}$ nodes of the southern transmission network in the case: a) without shunt compensation, b) with shunt compensation. All simulations are performed for the maximum load conditions. By comparing both cases, it seems evidently the difference in voltage levels, especially for $110 \mathrm{kV}$ nodes, where the voltage is improved from $91 \mathrm{kV}$ to $102 \mathrm{kV}$ for the furthest south nodes of Gjirokastra and Bistrica.
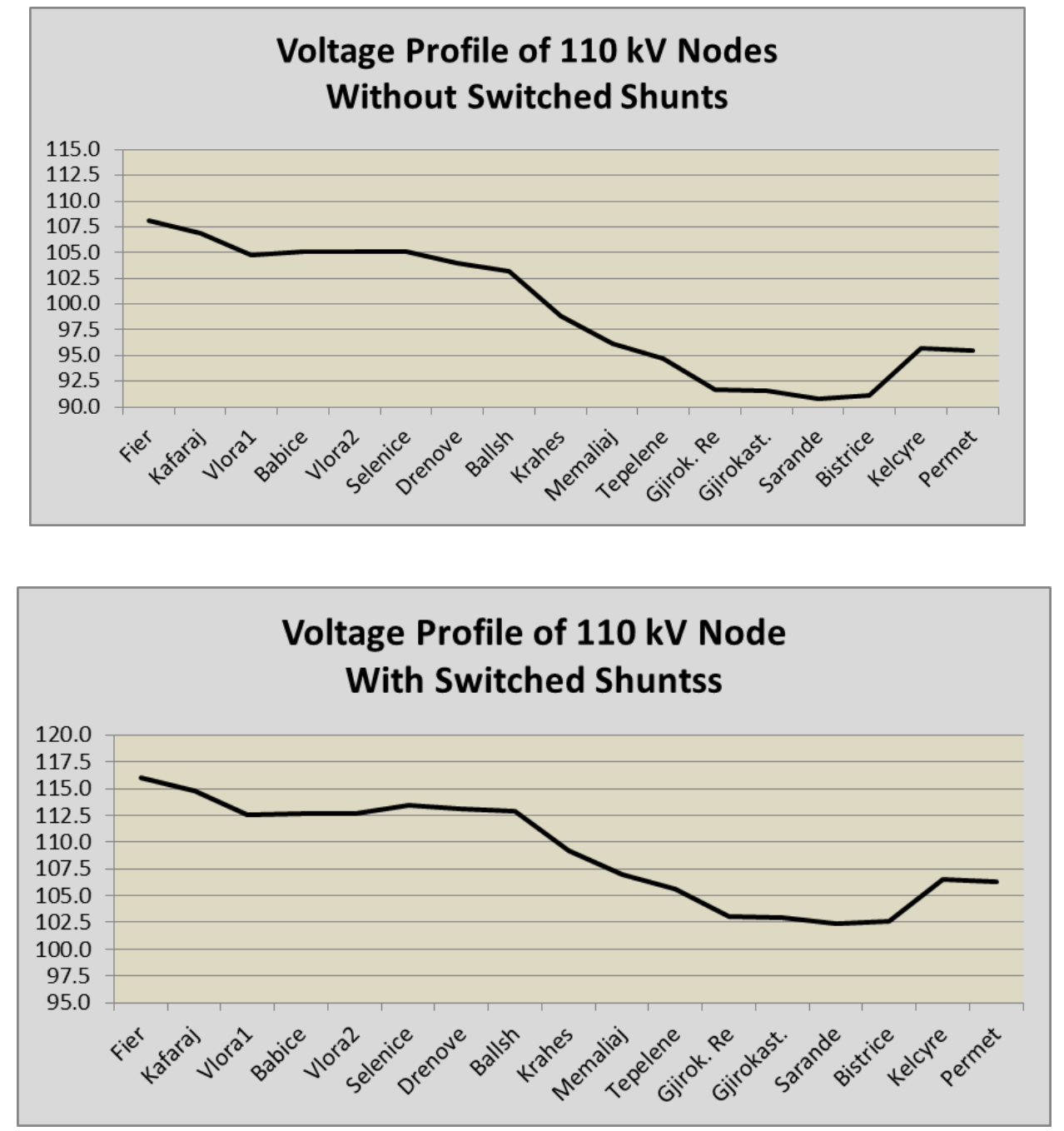

Fig.9 The simulating results for $110 \mathrm{kV}$ transmission nodes

Actually, in Albanian transmission system, there are installed three fixed capacitor banks (as a form of SVC device, see fig.4) $\mathrm{Q}_{\mathrm{C}}=45 \mathrm{MVAr}$, which operate in "switched mechanically" mode at $110 \mathrm{kV}$ level in the substations of Fier, Ballsh and Lushnja. These nodes are determined as critical points according to the consumption of reactive power. In the tables I and II are presented metering data of voltage for $110 \mathrm{kV}$ and $220 \mathrm{kV}$ level of transmission sy stem in two situations: a) without shunt, b) with switched shunt compensation, in case of maximum load. By comparing the metering results of tables I and II with simulation results of fig. 9 and 10, it seems clear the effect of shunt compensation in increasing the transmission voltage level with $7.5 \%$ for $110 \mathrm{kV}$ nodes and $6.1 \%$ for $220 \mathrm{kV}$ nodes [6]. This shows the efficiency of shunt compensation implementation, especially for $110 \mathrm{kV}$ transmission lines, which are directly connected with distribution network. 

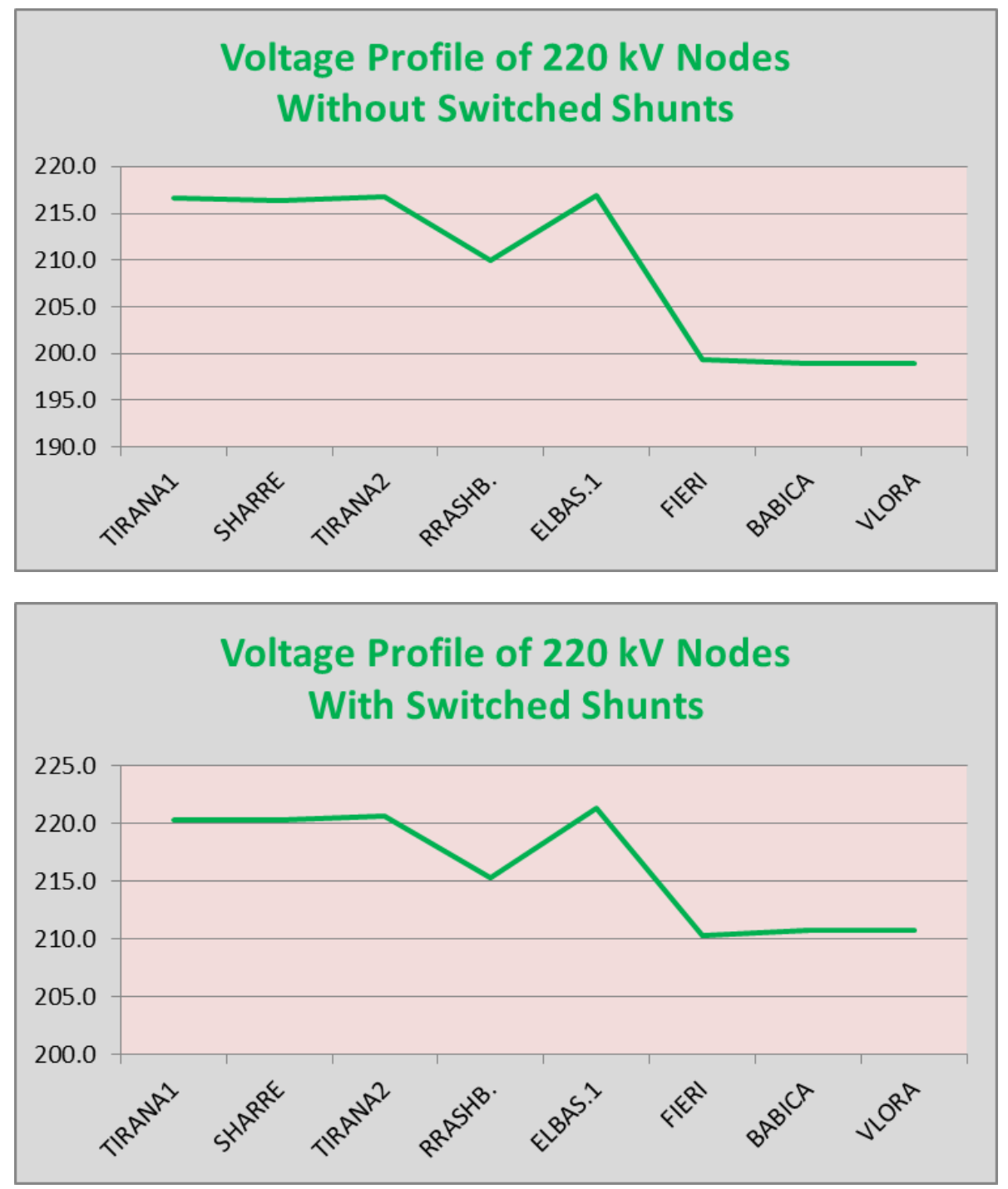

Fig.10. The simulating results for $220 \mathrm{kV}$ transmission node 
International Conference on Energy Efficiency Engineering, Nov 2015

TABLE I THE METERING DATA FOR 110KV SOUTHERN NODES

\begin{tabular}{|c|c|c|}
\hline \multirow{2}{*}{$\begin{array}{l}\text { Names of } \\
\text { Nodes }\end{array}$} & \multicolumn{2}{|c|}{ Voltage (kV) } \\
\hline & Without shunt & With switched shunt \\
\hline Fier & 105.14 & 113.82 \\
\hline Kafaraj & 104.5 & 113.11 \\
\hline Vlora-1 & 103.47 & 111.94 \\
\hline Babica & 104.74 & 112.93 \\
\hline Vlora-2 & 104.69 & 112.89 \\
\hline Selenica & 103.87 & 112.68 \\
\hline Drenova & 103.18 & 112.37 \\
\hline Ballsh & 102.71 & 112.21 \\
\hline Krahes & 100.97 & 109.51 \\
\hline Memaliaj & 99.91 & 107.84 \\
\hline Tepelena & 99.17 & 107.08 \\
\hline Gjirokaster & 97.8 & 105.62 \\
\hline Saranda & 98.96 & 106.44 \\
\hline Bistrica & 99.26 & 106.72 \\
\hline Kelcyra & 100.28 & 107.24 \\
\hline Permet & 100.7 & 106.99 \\
\hline
\end{tabular}

TABLE II THE METERING DATA FOR 220KV NODES

\begin{tabular}{|c|c|c|}
\hline \multirow{2}{*}{$\begin{array}{l}\text { Names of } \\
\text { Nodes }\end{array}$} & \multicolumn{2}{|c|}{ Voltage (kV) } \\
\hline & Without shunt & With switched shunt \\
\hline Tirana-1 & 213.43 & 217.50 \\
\hline Sharre & 213.68 & 218.04 \\
\hline Tirana-2 & 213.92 & 218.17 \\
\hline Rrashbull & 206.99 & 212.94 \\
\hline Elbasan-1 & 212.22 & 217.03 \\
\hline Fier & 196.26 & 208.22 \\
\hline Babica & 194.5 & 207.22 \\
\hline Vlora & 194.51 & 207.23 \\
\hline
\end{tabular}




\section{Conclusions}

The voltage level is an important aspect of power systems performance.

The paper presents the impact of shunt compensation devices in improving voltage levels for the some problematic overhead transmission lines of the Albanian power system.

The simulations results and metering data are complying with each-other. Considering the growth of voltage levels in the system, they are proof for the efficiency of this short-time investment in Albanian transmission network.

\section{References}

1. Machovski,J., Bialek, J.W., Bumby ,J.R.: Power Systems Dynamic and Control. Second Edition. Jown Willey \& Sons (2008) 41-54

2. Hingorani,N.G.: Understanding FACTS. IEEE Press. NJ,USA (2000)

3. CIGRE Task Force 38-01-02: Static Var Compensators (1986)

4. Gjini,L.: Pajisjet FACTS si alternative per zgiidhjen e problemeve te sistemit elektroenergjetik-nje procedure per percaktimin e vend-instalimit optimal. UPT (dissertation). (2008)

5. ERE: Annual reports. www.ere.gov.al. (2011-2015)

6. OST (Albanian Transmission Operator): Documentation of Development and Study Department. OST Archive (2015) 